\title{
Stakeholders' Role in Creativity: A Multidimensional Business Model for Arts Festivals
}

\author{
Stephen Boyle ${ }^{1}$, Carmen Haule Reaiche ${ }^{2}$ \\ ${ }^{1}$ Business School, University of South Australia, South Australia, Australia, \\ ${ }^{2}$ Entrepreneurship, Commercialisation and Innovation Centre, University of Adelaide, South \\ Australia, Australia
}

\begin{abstract}
This paper aims to empirically identify the key factors that drive effective innovative business models in the creative industries. There have been various approaches of analyzing the impact and importance of the creative industries but few appears to address the importance of major stakeholders driving innovation potential in this arena. A case study of the Moon Lantern Festival event held in Adelaide South Australia, where it is part of the OzAsia Festival has been adopted in this paper to underline the analyses of this study. Using a systems approach and stakeholder theory this research aims to develop a model that evaluates innovative business practices in major public Performing Arts Festivals. From the case study and its stakeholder analysis a new business model framework is proposed with a focus on organisational culture, idea generation, relationships and collaborations, team work and resource sharing.
\end{abstract}

Key words: Arts Festivals, Creative Industries, Stakeholders, Business Models, OzAsia Festival.

\section{INTRODUCTION}

The creative industries is a particularly complex field, in which organizations may generate unique business processes and also translate various forms of intellectual capital such as symbolic culture to social economic benefits. Little has been done to study new forms of business models that capture the value of innovation in this entrepreneurial arena, with most of the attention focusing on the artistic or creative process instead. This research aims to empirically identify the key factors that drive effective innovative business models in the creative industries. The Centre of Excellence for Creative Industries and Innovation (CCI) proposes that, in Australia, the creative industries are comprised of the following segments: a. Music and Performing Arts, b. Film, Television and Radio, c. Advertising and Marketing. d. Software Development and Interactive Content. e. Writing, Publishing and Print Media, and f. Architecture, Design and Visual Arts [1]. Performing Arts Festivals are key assets for major cities, they have an impact on the location's economy as well as social and cultural development.
They bring together a combination of key stakeholders while employing different business models (from government owned to commercial orientation) and as such they are complex in nature. These festivals are a good representation of the creative industries however, particularly in Australia, since 2006 according to the CCI report [2], the performing arts' segment itself has been the lowest contributor to the social economy. At the same time, many cities espouse the economic benefits derived from performing arts festivals. Therefore, it is considered timely to pilot and explore the role of performing arts festivals in this research. A case study of the Moon Lantern Festival event held in Adelaide South Australia, where it is part of the OzAsia Festival has been adopted in this paper to underline the analyses of this study. Using a systems approach and stakeholder theory this research will develop a model that evaluates innovative business practices in major public Performing Arts Festivals.

There have been various approaches to analyzing the impact and importance of the creative industries. Some have adopted a managerial and organizational practice approach while others focused on

Corresponding Author: Professor Stephen Boyle, Business School, University of South Australia, City West Campus, South Australia, +61 883020320 
innovation from a leadership perspective, taking the stand that the creative industries are the trigger of innovation in the social economy and product development [3]. Recently, Lampel and Germain [4] highlighted the need to look at creative industries as businesses and or enterprises that play a critical role in shaping the future of managerial processes that support economic development. They argue that: "The discourse of creativity that was at one point associated with impractical risk is now seen as key to economic success. This reversal in what managers look for when it comes to best practices means that creative industries are more likely than ever before to exercise influence on management thinking across a wide range of industries". This research explores the creative industries, and the performing arts festivals segment with this perspective in mind. As the environment in which creative industries operates reflects mainly the collaboration between various key stakeholders (i.e. society, enterprise, government, artist and others) effective business models need to account for this. Particularly when the creative industries are to influence managerial approaches supporting social-economic development. Here, business models are to be bound to managerial processes that are innovative and quick to adapt to new business environments. The main question is, are the segments of the creative industries aware of this?

Understanding the nature of business models of performing art festivals is central to identifying their potential for development and innovation. In the following, we provide a framework for such understanding. In order to do so, we first define creative industries, focusing on festivals as their avenue, and review its impact on society. By 'society' we mean the contributions and offerings of the creative industries including cultural inclusion, performances, services and deliverables to their stakeholders (we use the term society to denote all these). Next, we identify Innovation as a driver and service of effective business models. Particular focus is given to 'open innovation' as this has differential effects in business models and stakeholders. Finally, we use a case study of the Moon Lantern Festival event held in Adelaide South Australia and we identify factors that intertwine all: key success factors on business models, industry organization, and ultimately innovation.

\section{CREATIVE INDUSTRIES: ARTS FESTIVALS SEGMENT}

In 2008 the UNCTAD's report [5] brought the term "Creative industries" to the fore: "the interface between creativity, culture, economics and technology as expressed in the ability to create and circulate intellectual capital, with the potential to generate income, jobs and export earnings while at the same time promoting social inclusion, cultural diversity and human development. This is what the emerging creative economy has already begun to do.' The creative industries are regularly defined in terms of an industrial segment guided by the nature of their operations, their core business, and approach. The creative industries are thus implicitly defined and classified according to industrial sectors. UNCTAD has been able to develop a sectoral taxonomy of the creative industries between the segments identified by the CCI and a much wider network including the general arts, media, heritage, and "functional creations" or more service-oriented sectors. However, there has been much debate since about an appropriate definition for it. Therefore, we considered appropriate to provide an overview of these broader set of categories, and highlight the Arts Festival as a key segment that constitute the Creative Industries worldwide and the focus of this research.

Arts festivals play a crucial role in the creative industries; yet their significance in the creative sector has been largely overlooked. Festivals are now a common component of most cities' cultural calendars. Some of these festivals are specifically linked to the cultural identity of the region but others are increasingly becoming more generic in nature or globalised in the content they present. In all circumstances however there is a need to measure success of such events. This raises the question of why some festivals are more successful than others.

Reviewing some key literature, for instance Hall [6] in his book "Hallmark Tourist Events: impacts, management and planning" argues that other socio economic impacts, like environmental, socio cultural and political effects have a more long term impact and are more important than economic ones. In addition, Richie [7] and Getz [8], in their early work of event tourism, clearly established a variety of potential festivals' impacts other than economic, including social, cultural, political, physical and environmental ones. What is more, they argued that these impacts are not always captured at the time of the event, but rather through conducting an evaluation of the impacts occurring before, during and after the event. Examples of impact assessments that have paid significant attention to non-economic impacts are also found in studies by Hamilton et al [9] who focuses on cultural impacts before and after the Highland Year of Culture studying, in particular, the impact of this event on Gaelic speakers and on school children's language programs in various regions of Scotland. Similar argument can be found in the work of Carlsen et al [10] and Chouguley et al [11] on the impact of the Edinburgh Festivals, both works clearly pleading for researchers to move beyond economic impacts of festivals in order to 
develop explicit understanding of the complexities and comprehensive sets of benefits associated with this event. They call for a more holistic approach, one which incorporates a systematic study of all key elements and actors associated with festivals and which also encourages innovation.

We aren't arguing which particular element has more or less effect but rather that we need to understand further these indirect impacts and influences. Therefore, the paper proposes a stakeholder framework of analysis as this will facilitate an understanding of what value festivals really bring and for whom, so we may better gauge success. The approach presented in this paper is of a systems view, the system in which the festival operates, taking into account all the elements that are affected by such events and aiming to build sustainable business models in this arena. If the creative industries are to really be seen as a major driver of the broader innovation agenda, business models that are connected to innovation, and are sustainable as well as competitive, are a must. By identifying and understanding the role of key stakeholders, integrating their objectives and aligning these with the core mission of the creative industries, we are a step closer to adopting business models that creates business success, and that encourages innovation, both aspects critical to competitive advantage.

\section{BUSINESS MODELS AND INNOVATION: A STAKEHOLDER'S APPROACH}

Business model frameworks are a key component of business strategy and closely linked to innovation management [12][13]. The practical appeal of business models in the management discipline, and innovation in particular, lies in its facilitation to identify, integrate and evaluate the key elements of how businesses innovate and how businesses provide value to their customers maintaining their competitive capabilities. Business models provide a framework to describe and define an enterprise and its activities [14]. Identifying the components of the total business and its activities are required to ensure the full enterprise model is depicted and allows comparisons between enterprises. These comparisons can then provide insights into how one organisation is able to more successfully convert innovative concepts into commercially reality.

Teece [15] notes however that when enterprises think about innovation they rarely consider the adoption of in-depth analysis to build appropriate business models that translate "technical success into commercial success" (pp. 184). This highlights that an effective business model design is one that allows innovation to succeed technologically in a commercial context. Getting both the business model and innovation strategy right "is necessary to achieve commercial viability if sustainable competitive advantage is to be built" [15:184]. Finally, Teece concludes the need for greater understanding and appreciation of the importance of developing new business models and the exploration of the key elements or factors that will make the link between enterprise strategies and innovation capabilities. A systems' view of the creative industries and stakeholders' analysis can provide a strategy for these business models.

According to Jalonen [16] innovation has significant elements of uncertainty and there is real potential for value creation not to be realised. Teece [14] agrees that capturing the value from innovation is a key element of the business model. However, given the perceived important of business model design in sustainable innovation practices, it is interesting to note that in Jalonen's review of the innovation literature, out of 112 critical articles, only one discusses business models, and this appeared to have taken a profit market-demand orientation rather than a business-management and strategy approach [17] . It is here that we see the value of a stakeholder approach, which when applied earlier, it could drive innovation practices to sustainable managerial processes.

De Medeiros, et al. [18] undertook a review of literature with the aim to map critical success factors that drive innovation. In their review they identified a number of key factors which included external and internal key factors. External factors were listed as market collaborations, business communities, social networks and legislation. The internal factors were listed as the standard R\&D investment, but more importantly, the "Interfunctional collaboration" and Innovation-oriented creative learning that eventuates when open communication (with both, internal and external parties) prevails. De Medeiros et al [18] found that interfunctional collaboration requires individuals in the organisation to be able to collaborate across functional areas as well as between different components within the internal and external stakeholders

It would appear then that it is critical to understand how individuals within the organisation interact, understand and integrate innovation. Searching for a more unified definition of innovation begins with how individuals collaborate towards business models that are sustainable and enablers of innovation. The effort to measure attitudes, opinions, and disposition of individuals towards innovation builds on a multidisciplinary body of literature from culture, diversity, globalization, and 
strategy. This paper presents an approach to explore who the creative industries have an effect on, by using Stakeholder Theory and adapting it to a festival setting. Edward Freeman in his book Strategic Management: A Stakeholder Approach [19] states that Stakeholder Theory is an idea about how business really works. It says that for any business to be successful it must create value for customers, financiers, suppliers, employees, government, communities and shareholders. It says that you can't look at any one of these stakeholders in isolation. Their interests should go together, and the job of a manager is to work out how to ensure the interests of customers, suppliers, communities, employees and financiers go in the same direction or align. Stakeholder Theory suggests that sustained success only comes when all stakeholder interests are aligned and therefore we consider this critical for the creative industries.

\section{THE STUDY: THE MOON LANTERN FESTIVAL CASE STUDY}

This research is case based and case centered, therefore we focused on one case, simultaneously taking into account the context to incorporate many variables and qualities.

Three main requirements for adopting a case study approach should be validated [20] [21] [22] [23] as per below:

a. The clear identification and focus on a "case" as the object of the study. The Moon Lantern Festival event held in Adelaide South Australia, where it is part of the OzAsia Festival was found appropriate as it has a clear focus on the field of study: The Creative Arts. b. The "case" should be operating and show a degree of complexity in order to be investigated in its natural system (i.e. environment). The Moon Lantern Festival has different management layers and a wide interaction of stakeholders, therefore it shows a degree a complexity.

c. The "case" should be current. The Moon Lantern Festival is an annual event and when researched, in addition to historical data, the data collated via interviews were current to the event taken place.

The case study selected was expected to capture the complexities of the business processes and stakeholders' participation. In the process of evaluating the interests of all stakeholders, as Freeman suggests, a qualitative approach was best suited. Interviews were conducted with current and past festival directors, the CEO of the umbrella organisation (The Adelaide Festival Centre) and Government bodies' representatives.

The following framework (Figure 1) displays an adaption of the Stakeholder model developed by Freeman [19] which it's applicable to the specific setting of a creative industry: arts festivals. The different stakeholders were identified through interviews with the festival directors and subsequently aligned to Freeman's framework. With this case the paper proposes that successful creative industries will demonstrate innovation alignment among the different stakeholder groups. In fact when all these stakeholder groups come together they create something that individually would not be possible. In this way the creative industries will become a core component of the cultural fabric of the community, and therefore more sustainable.

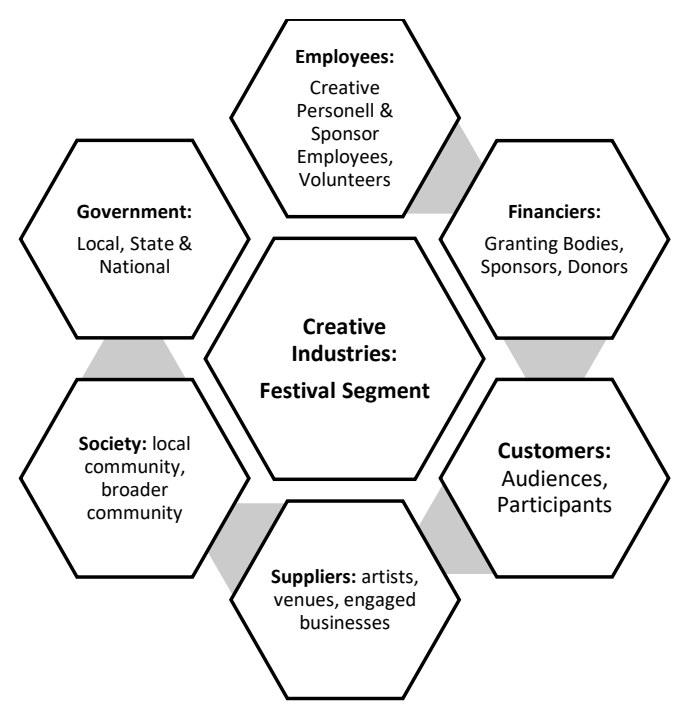

Fig. 1: A Stakeholder Map for the Creative Industries 
The above framework was then used to analyse the case study of the Moon Lantern Festival event held in Adelaide South Australia, where it is part of the OzAsia Festival. The Moon Lantern Festival is a celebration of the Mid-Autumn Festival, a harvest festival celebrated by ethnic Chinese and Vietnamese peoples. The festival is held on the 15 th day of the eighth month in the Chinese Han calendar and Vietnamese calendar (within 15 days of the autumnal equinox), on the night of the full moon between early September to early October. The holiday is also celebrated in Korea (Chuseok) and Japan (Tsukimi).

The OzAsia Festival is an annual multi-arts festival created by the Adelaide Festival Centre. It was first held in 2007 and has grown in success and stature since its first festival. As noted by the Executive Producer of the first festival in 2007:

"OzAsia reflects cosmopolitan Australia. As the creative heart of South Australia the Adelaide Festival Centre presents OzAsia in a spirit of recognition of diverse contributions, regional exchange and cultural excellence." [NS]

The Moon Lantern Festival is a free event in a large park in the city. It involves professional performers as well as school and community groups. This event has been a central component of the OzAsia Festival since its inception. The idea for the Moon Lantern Festival came from the creator of the OzAsia Festival, CEO of the Adelaide Festival Centre. He noted that one day while walking through Chinatown he saw children with lanterns playing in the street celebrating the Mid-Autumn Festival:

"Ït was at that moment that I thought, wouldn't it be wonderful if there was a parade or event that these children and others in the community could gather to celebrate this event more formally" [DG].

One key aspect of the festival was the incorporation of school children into the festival through both practical workshops, performances and curriculum based activities. Almost 2,000 South Australian students engaged with studies of Asia through their involvement in the Moon Lantern Parade during the first year of the event. This participatory involvement was made possible through a collaboration with the State Government's Department of Education and Children's Services. Collaboration and innovation being the two key drivers here for this process to eventuate.

The parade also included many hundreds of the school children who had become involved through curriculum activities around educating them of the different cultures across the Asian region. The students work with artists to make lanterns which they then carry in the parade. Event sponsors continue to promote these community activities through programs where employees can also take part in lantern making or even drumming workshops leading up to the festival event.

The event also provides creative and cultural opportunities for employees and families of the sponsors of the festival. Groups can be involved in lantern making workshops, drumming workshops and other activities. These groups then take part in the Lantern Parade alongside the many professional artists and groups.

Since 2007 the Moon Lantern Festival has become a major focal point for many community groups and interested businesses and government departments. The audience numbers have grown significantly as has the involvement of community groups, businesses and schools. In 2014 almost 60 different groups were involved in the event. These included cultural associations, schools and arts organisations, both professional and community-based. The Moon Lantern Festival now incorporates a number of public event benefits as well as many participative activities that run for much longer periods of time leading up to the parade itself.

In 2015 the festival attracted over 50,000 people to the event and associated activities. It is now Australia's largest lantern parade, and included over 1200 performers in the lantern parade as well as other activities such as Bollywood dancing, martial arts demonstrations, roving circus performances, a Lion Dance, music and fireworks.

With such a large outdoor free event, there is considerable community building opportunities which provide direct tangible benefits to funders and governments. Many businesses sponsor giant lanterns, which then display their logos in many creative and imaginative ways. In addition, the media exposure generated by the event is invaluable for showcasing the City of Adelaide and State of South Australia. Professional artists also enjoy the public relations benefit of their involvement in the parade and free festival event.

The event successfully brings together the many stakeholders with corporate functions, government officials, community engagement, media attention, education and tourism offshoots, Public Relations opportunities and much more. Each stakeholder has a specific set of goals and values it wishes to attain from its involvement in the festival. The festival management has worked to align these different stakeholder groups so that individual needs are met through the many facets of the event. The most significant stakeholder however is the community itself. As noted by the CEO when discussing the success of the Moon Lantern Festival, he clearly stated that:

"without the community, there would be no festival”. [DG]

Since commencing in 2007, this event has grown in size and significance to the local community. It has 
grown beyond a cultural festival to become a major artistic event and community building event, which spans schools, major companies and sponsors, government and local businesses that benefit from the ongoing engagement of the event.

\section{DISCUSSION}

From the Moon Lantern Festival case we can see that the following factors would appear to have a significant level of influence over whether an organisation can create new ideas and turn them into new innovations and sustainable success:

1. A supportive, inclusive and adaptive organisational culture

2. The ability to create and evaluate new ideas

3. Structures that are built around teams and groups

4. An emphasis on relationships, both internal and external, particularly the community

5. A focus on collaboration with different actors and stakeholders

6. The availability of the required resources including talent

In the past, traditional business models were based on hierarchy, structures, individuals, competition, rules, authority and exclusivity. However new business models will need to be based on concepts such as idea sharing, inclusivity, integration, collaborations and alliances, teams and relationships and most importantly organisational culture.

For creativity to flourish within organisations and for this creativity to be harnessed for commercial innovation, new business models must be developed to allow for collaboration and knowledge sharing. Rather than seeing external parties as competitors, those working in the creative industries need to see them as collaborators. Direct competition actions need to be turned into alliance building activities. Organisations need to be able to identify talent both internal and external to the organisation. In that way they can develop networks of experts, working together, sharing ideas and developing concepts. At that point the organisational internal processes can take the concepts and move to commercialisation.

It is crucial for organisations to understand the role of culture in either fostering or stifling innovation. Perhaps there is a need to reassess the role of leadership and management within the organisation, to move from a directorial role to a more facilitator role. Innovation and creativity are human activities and as such the development of skills of the employees will be crucial. They will also need to think about what will be the best mechanisms for knowledge and idea sharing within the organisation, across functional areas and with key actors outside the organisation. There will be a need to find and manage the required resources which may offer new opportunities for resource sharing rather than monopolising and controlling resource allocation.

\section{CONCLUSION AND FUTURE RESEARCH}

This paper serves to contribute to the debate on the need for new business models in the creative industries in which stakeholders play an important role to assist innovation. It is not the intention to present innovation as a panacea or a diametrically opposed alternative to traditional forms of business models in the creative sector. Instead, the notions of stakeholder theory taking into account the complexities of the system in which the creative industries operates is proposed for future research. The paper presented a stakeholder analysis and based on the case study we propose an exploratory model (Figure 2) where we intertwine the main factors identified from the case study into the following clusters:

1. Knowledge networks: identified by interviewees as one of the critical components to generating new ideas and in which collaboration serves as a catalyst to generate mechanisms to transform business models into long term sustainable ones

2. Internal/external environments: identified by interviewees through the importance of the need to integrate systems that will enable the appropriate networks that will generate the above knowledge and collaborations

3. Stakeholders: identified by interviewees through their acknowledgement of the importance of the recognition of key stakeholders' participation in the decision processes

This can serve as a model to test more widely and assess the reliance of each factor in different creative industry settings. 
Fig. 2: Future Research: A Multidimensional Business Model Framework

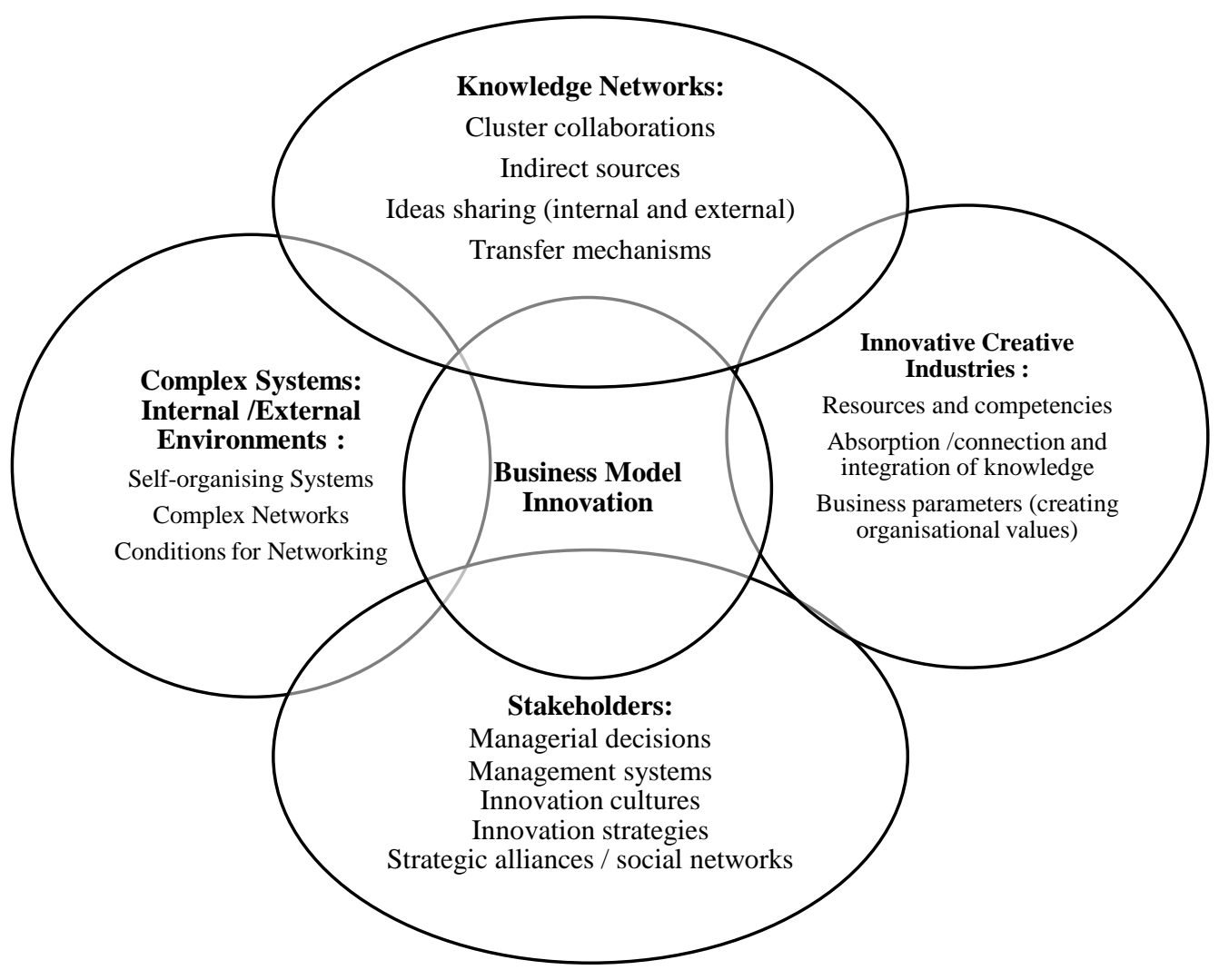

\section{REFERENCES}

[1] Higgs, P., Cunningham, S., and Bakhshi, H. (2008). Beyond creative industries: Mapping the creative economy in the UK. London: NESTA.

[2] CCI. (2007). Australian Research Council Centre of Excellence for Creative Industries and Innovation Report. Brisbane: Australia.

[3] Lampel, J., Lant, T., and Shamsie, J. (2000). "Balancing act: Learning from organizing practices in cultural industries". Organization Science, Vol. 11, no 3, p. 263-269.

[4] Lampel, J. and Germain, O. (2016). "Creative industries as hubs of new organizational and business practices". Journal of Business Research, Vol. 69, p. 2327-2333.

[5] United Nations Committee on Trade, Aid and Development. (2008).

[6] Hall, C. (1992). Hallmark Tourist Events: impacts, management and planning. London: Belhaven Press.

[7] Richie, J. (1984). "Assessing the impact of hallmark events: conceptual and research issues". Journal of Travel Research, Vol. 22, no 1, p. 2-11.
[8] Getz, D. (1997). Event Management and event tourism. New York: Cognizant Communication Corporation.

[9] Hamilton, C., Galloway, S., Langen, F., Cran, A, MacPherson, C., Burns, M., and Snedden, E. (2008). Evaluation report: Scotland's Year of Highland Culture 2007. Glasgow: University of Glasgow, Centre for Cultural Policy Research.

[10] Carlsen, J., Ali-Knight, J. and Robertson, M. (2007). "ACCESS - a research agenda for Edinburgh Festivals". Event Management, Vol. 11, no $1 / 2$, p. 3-11.

[11] Chouguley, U., Naylor, R. and Rosemberg Montes, C. (2011). Edinburgh Festivals Impact Study Report May 20122. BOP Consulting.

[12] Gronum, S., Steen, J., and Verreynne, M. (2016). "Business model design and innovation: Unlocking the performance benefits of innovation". Australian Journal of Management, Vol. 41, no 3, p. 585-605.

[13] Lambert, S. and Davison, R. (2012). "Applications of the business model in studies of enterprise success, innovation and classification: An analysis of empirical research from 1996 to 2010" . 
European Management Journal, Vol. 36, no 6, p. 668-681.

[14] Teece, D.J. (2009). Dynamic Capabilities and Strategic Management: Organizing for Innovation and Growth. Oxford University Press, Oxford, New York.

[15] Teece, D.J. (2010). "Business models, business strategy, and innovation". Long Range Planning, Vol. 43, p. 172-194.

[16] Jalonen, H. (2012). "The uncertainty of innovation: a systematic review of the literature". Journal of Management Research, Vol. 4, no 1, p. 147.

[17] Verhees, F. and Meulenberg, M. (2004). "Market Orientation, Innovativeness, Product Innovation, and Performance in Small Firms". Journal of Small Business Management. Vol. 42, no 2, p. 134-154.
[18] De Medeiros, J., Duarte Ribeiro, J. and Cortimiglia, M. (2014). "Success factors for environmentally sustainable product innovation: a systematic literature review". Journal of Cleaner Production, Vol. 65, p. 76-86.

[19] Freeman, E. (1984). Strategic Management: a stakeholder approach. Boston: Pitman.

[20] Yin, Robert. (1994). Case Study Research: Design and Methods. Thousand Oaks, London, New Delhi: Sage

[21] Merriam, S., (1988). Case Study Research in Education. San Fransico: JosseyBass Inc. Publ.

[22] Stake, R. (1995). The Art of Case Study Research. Thousand Oaks, London, New Delhi: Sage.

[23] Miles, M. and Huberman, A. (1994). Qualitative Data Analysis. Thousand Oaks: Sage. 